\title{
Age-related carbon dioxide reactivity in children after moderate and severe traumatic brain injury
}

\author{
Tensing Maa, MD, ${ }^{1}$ Keith Owen Yeates, PhD, ${ }^{2}$ Melissa Moore-Clingenpeel, MAS, ${ }^{3}$ and \\ Nicole F. O'Brien, MD'1
}

\begin{abstract}
'Nationwide Children's Hospital and 'Research Institute at Nationwide Children's Hospital, Columbus, Ohio; and 2University of Calgary, Alberta, Canada
\end{abstract}

\begin{abstract}
OBJECTIVE The objective of this study is to assess carbon dioxide reactivity $\left(\mathrm{CO}_{2} \mathrm{R}\right)$ in children following traumatic brain injury (TBI).

METHODS This prospective observational study enrolled children younger than 18 years old following moderate and severe TBI. Thirty-eight mechanically ventilated children had daily $\mathrm{CO}_{2} \mathrm{R}$ testing performed by measuring changes in their bilateral middle cerebral artery flow velocities using transcranial Doppler ultrasonography (TCD) after a transient increase in minute ventilation. The cohort was divided into 3 age groups: younger than 2 years $(n=12) ; 2$ to 5 years old $(n=9)$; and older than 5 years $(n=17)$.

RESULTS Children younger than 2 years old had a lower mean $\mathrm{CO}_{2} \mathrm{R}$ over time. The 2-5-year-old age group had higher mean $\mathrm{CO}_{2} \mathrm{R}$ than younger patients $(p=0.01)$, and the highest $\mathrm{CO}_{2} \mathrm{R}$ values compared with either of the other age groups (vs $>5$ years old, $p=0.046$; vs $<2$ years old, $p=0.002$ ). Having a lower minimum $\mathrm{CO}_{2} \mathrm{R}$ had a statistically significant negative effect on outcome at discharge $(p=0.0413)$. Impaired $\mathrm{CO}_{2} \mathrm{R}$ beyond Postinjury Day 4 trended toward having an effect on outcome at discharge $(p=0.0855)$.
\end{abstract}

CONCLUSIONS Abnormal $\mathrm{CO}_{2} \mathrm{R}$ is prevalent in children following TBI, and the degree of impairment varies by age. No clinical or laboratory parameters were identified as risk factors for impaired $\mathrm{CO}_{2} \mathrm{R}$. Lower minimum $\mathrm{CO}_{2} \mathrm{R}$ values are associated with worse outcome at discharge.

http://thejns.org/doi/abs/10.3171/2016.1.PEDS15564

KEY WORDS pediatric traumatic brain injury; carbon dioxide reactivity; transcranial Doppler ultrasound; cerebrovascular reactivity; trauma

$\mathrm{T}$ RAUMATIC brain injury (TBI) is the leading cause of disability and death in children in the United States and accounts for more than 2600 deaths and 37,000 hospitalizations per year. ${ }^{6}$ Severe TBI management guidelines recommend targeting age-specific cerebral perfusion pressure (CPP), managing intracranial hypertension $(\mathrm{ICH})$, and minimizing secondary brain injury through the avoidance of hypoxia, hypotension, hyperthermia, hyperglycemia, and hypo- or hypercarbia. ${ }^{12,27}$ Despite these management strategies, there has been little improvement in neurological outcomes after severe TBI over the past 2 decades. ${ }^{25}$ Among the pediatric age group, there is a difference in outcome with increasing age., ${ }^{3,7,15,16}$ In particular, children younger than 2 years may have worse outcomes than older children. ${ }^{1,2}$ A greater understanding of the pathophysiological changes that occur in the pediatric brain following moderate and severe TBI is needed to identify alternative, additional, or individualized treatment approaches that may benefit these children.

Cerebrovascular reactivity (CVR) reflects the normal response of the cerebral arterioles to changes in physiological stimuli, such as the partial pressure of arterial carbon dioxide $\left(\mathrm{PaCO}_{2}\right)$. Under normal conditions, increased concentrations of $\mathrm{PaCO}_{2}$ result in the vasodilation

ABBREVIATIONS AHT = abusive head trauma; $\mathrm{CBF}=$ cerebral blood flow; $\mathrm{CO}_{2} \mathrm{R}=$ carbon dioxide reactivity; $\mathrm{CPP}=$ cerebral perfusion pressure; $\mathrm{CVR}=$ cerebrovascular reactivity; $\mathrm{ETCO}_{2}=$ end-tidal $\mathrm{CO}_{2} ; \mathrm{GCS}=$ Glasgow Coma Scale; GOS-E Peds = Glasgow Outcome Scale Extended Pediatric Version; ICH = intracranial hypertension; ICP = intracranial pressure; $\mathrm{MOI}=$ mechanism of injury; $\mathrm{PaCO}_{2}=$ partial pressure of arterial carbon dioxide; PID = Postinjury Day; $\mathrm{ROC}=$ receiver operator characteristic; TBI = traumatic brain injury; $T C D=$ transcranial Doppler ultrasonography; $\mathrm{V}_{\mathrm{MCA}}=$ mean blood flow velocity of the right and left middle cerebral arteries.

SUBMITTED September 21, 2015. ACCEPTED January 20, 2016.

INCLUDE WHEN CITING Published online April 1, 2016; DOI: 10.3171/2016.1.PEDS15564. 
of these vessels with the subsequent increase in cerebral blood flow (CBF), ${ }^{9,32}$ while decreased concentrations of $\mathrm{PaCO}_{2}$ have the opposite effect. Additionally, $\mathrm{CO}_{2}$ reactivity $\left(\mathrm{CO}_{2} \mathrm{R}\right)$ and $\mathrm{CBF}$ are higher at baseline in children than adults. ${ }^{10,14,26,29,31,33}$ These expected vasomotor responses to changes in $\mathrm{PaCO}_{2}$ can be affected by several pathological processes, including TBI. Impaired CVR may result in cerebral hyperemia or ischemia with changes in CPP. Children may have less tolerance for alterations in cerebral hemodynamics and thus be at higher risk for sustaining secondary brain injury. Multiple studies in adults have shown a link between impaired $\mathrm{CO}_{2} \mathrm{R}$ and poor neurological outcomes. ${ }^{8,13,21,28}$ Much less is known about $\mathrm{CO}_{2} \mathrm{R}$ impairment and its effects on outcome following TBI in children.

It is important to understand how vasoreactivity is altered in children after TBI and the relationship between decreased $\mathrm{CO}_{2} \mathrm{R}$ and outcomes. Thus, we sought to 1) describe differences in the temporal pattern and prevalence of impaired $\mathrm{CO}_{2} \mathrm{R}$ in different age groups after moderate and severe TBI; 2) examine if predictors of outcome after head injury such as age, Glasgow Coma Scale (GCS) score, and intracranial pressure (ICP) are important determinants of impaired $\mathrm{CO}_{2} \mathrm{R}$; and 3) correlate impaired CVR with outcome as measured by the Glasgow Outcome Scale Extended Pediatric Version (GOS-E Peds) at discharge and the 3-month follow-up.

\section{Methods \\ Study Population}

This study was part of a larger prospective observational study of children with TBI that was performed at a tertiary care, Level 1 , pediatric trauma center. The study was approved by the institutional review board of The Research Institute at Nationwide Children's Hospital, and informed consent was obtained from parents before enrollment. Children between the ages of 1 day and 17 years who were admitted to the pediatric intensive care unit with a diagnosis of moderate to severe head trauma (postresuscitation GCS score $\leq 12$ ), abnormal head imaging, and tracheal intubation were included. Children were excluded if they were deemed to have suffered a nonsurvivable injury, had a GCS score of 3 with fixed and dilated pupils, and death was imminent. Children were also excluded if they had a previous diagnosis of severe developmental disability or mental retardation because the interpretation of clinical outcome would be difficult. Demographic data including age, sex, mechanism of injury (MOI), Injury Severity Score, and postresuscitation GCS score were obtained.

\section{Clinical Management Protocol}

Patients with severe TBI were treated according to the 2012 guidelines for the acute medical management of severe pediatric TBI. ${ }^{12}$ Care included mechanical ventilation, elevation of the head of the bed to $30^{\circ}$, sedation, seizure prophylaxis, and placement of an ICP monitor with CSF drainage if ventriculostomy was performed. Age-appropriate CPP (neonates $\geq 40 \mathrm{~mm} \mathrm{Hg}$, children $50-60 \mathrm{~mm}$ $\mathrm{Hg}$, and adolescents $>60 \mathrm{~mm} \mathrm{Hg}$ ) was maintained using fluid boluses and vasopressors if needed. Persistent elevation in ICP $(\geq 20 \mathrm{~mm} \mathrm{Hg})$, despite these therapies, was treated with the institution of paralytics and hyperosmolar therapy. Hyperventilation, barbiturate coma, and decompressive craniectomy were used for refractory elevations in ICP.

\section{$\mathrm{CO}_{2} \mathrm{R}$ Testing}

Transcranial Doppler ultrasonography (TCD) was performed at the patient's bedside by 1 of 2 sonographers using a 2-MHz pulsed probe and commercially available TCD ultrasonography unit (Sonara Digital TCD; CareFusion). Training sessions prior to this study were performed to ensure $a<10 \%$ coefficient of variation in measurements between sonographers. Initial TCD recordings were performed within 24 hours of the injury, and daily examinations were done thereafter. The clinical care team was blinded to the findings of the TCD examinations. All studies, including those obtained from patients who were nearing brain death, were included in the analysis.

The end-tidal $\mathrm{CO}_{2}\left(\mathrm{ETCO}_{2}\right)$ concentration was monitored in all patients. $\mathrm{CO}_{2} \mathrm{R}$ was tested using previously described methods. ${ }^{8}, 11$ Testing was performed only in intubated patients who could have their $\mathrm{ETCO}_{2}$ decreased by at least $5 \mathrm{~mm} \mathrm{Hg}$ and were hemodynamically stable. Minute ventilation was transiently increased by altering the respiratory rate while $\mathrm{ETCO}_{2}$ was monitored. The mean blood flow velocity of the right and left middle cerebral arteries $\left(\mathrm{V}_{\mathrm{MCA}}\right)$ was evaluated at baseline and then immediately again after $\mathrm{ETCO}_{2}$ had decreased by at least $5 \mathrm{~mm} \mathrm{Hg}$ and remained stable for more than 2 minutes in order to achieve steady-state conditions. ${ }^{10}$ Heart rate, mean blood pressure, and body temperature remained unchanged throughout the study period. Relative $\mathrm{CO}_{2} \mathrm{R}$ was determined by calculating the ratio of percent change in $\mathrm{V}_{\mathrm{MCA}}$ per $\mathrm{mm} \mathrm{Hg}$ change in $\mathrm{ETCO}_{2}\left(\% \Delta \mathrm{V}_{\mathrm{MCA}} / \mathrm{mm} \mathrm{Hg}\right){ }^{11}$ $\mathrm{CO}_{2} \mathrm{R}$ testing was not performed on days when the patient already had an $\mathrm{ETCO}_{2}$ less than $35 \mathrm{~mm} \mathrm{Hg}$ in order to prevent any additional harm from hypoperfusion and secondary ischemia from vasoconstriction. A normal range of $\mathrm{CO}_{2} \mathrm{R}$ in children anesthetized with propofol has previously been defined as $10.3 \%$ to $13.8 \% .^{10}$

\section{Clinical Outcome}

Short-term outcome was assessed at the time of discharge from the hospital and again at 3 months after discharge using GOS-E Peds. This provides an age-appropriate, valid measurement of neurological outcome for infants and children younger than age 18 years with TBI. ${ }^{4}$ The 8 categories in the scale are: 1) upper good recovery; 2) lower good recovery; 3) upper moderate disability; 4) lower moderate disability; 5) upper severe disability; 6) lower severe disability; 7) vegetative state; and 8) death. For this study, good neurological outcome was considered to be a GOS-E Peds score $\leq 4$, and a poor neurological outcome was considered to be a GOS-E Peds score of 5 to 8 . The patient population was divided into 3 age groupsyounger than 2 years, 2 to 5 years old, and older than 5 years-due to the different tests that were needed to accomplish formal neurodevelopmental assessment. 


\section{Statistical Analysis}

For each variable studied, standard descriptive statistics were calculated, and distributions were examined to verify normality and equality of group variances; nonparametric procedures were implemented when either assumption was violated. Due to small sample numbers, all analyses were restricted to data obtained during the first 7 days. For continuous measures, 1-way ANOVA or the Kruskal-Wallis test was used to determine any overall age group differences; pairwise comparisons with the Tukey adjustment for multiplicity were used to further examine any statistically significant between-group effects. Differences in continuous measures between the moderate and severe TBI groups were assessed using the independentsamples t-test or Wilcoxon rank-sum test, as appropriate. All associations between categorical variables were examined using the Fisher's exact test. Receiver operator characteristic (ROC) curve analysis was performed to define a threshold value for predicting favorable versus unfavorable outcomes. The optimal value was determined by minimizing Youden's $\mathrm{J}$ statistic $(\mathrm{J}=$ sensitivity + specificity -1 ). This cut-point value was used to define abnormal $\mathrm{CO}_{2} \mathrm{R}$ for this study. Linear and generalized linear (binomial with a logit link function) mixed models were used to determine important predictors of mean $\mathrm{CO}_{2} \mathrm{R}$ and abnormal $\mathrm{CO}_{2} \mathrm{R}$ over time, respectively. To improve the stability and validity of the mixed models, patients for whom only 1 measurement was obtained were excluded. Interactions between each predictor variable and day of measurement were examined, as well as whether there were any univariate main effects on $\mathrm{CO}_{2} \mathrm{R}$. Important predictors of outcome were assessed using univariate ordinary least squares and logistic regression models. A 2-sided probability level of less than 5\% ( $\mathrm{p}<0.05)$ was considered significant. All analyses were performed using SAS (version 9.3; SAS Institute).

\section{Results}

Thirty-eight children (age range 1 day to 15.5 years) who were receiving mechanical ventilation following moderate or severe head trauma were included. The cohort included 28 male and 10 female patients. Seven patients underwent decompressive craniotomy upon admission, and this had no relationship with hemispheric or global $\mathrm{CO}_{2} \mathrm{R}(\mathrm{p}=0.8)$. One patient was treated with barbiturate coma for fulminant, refractory intracranial hypertension. The patient population was divided into 3 age groups: under 2 years old $(\mathrm{n}=12 ; 31 \%), 2$ to 5 years old $(\mathrm{n}=9$; $24 \%)$, and older than 5 years $(n=17 ; 45 \%)$. Table 1 shows the descriptive statistics by age group. Those patients with severe TBI $(n=30)$ were evenly split between 5 years or younger and older than 5 years old.

\section{Prevalence Of Abnormal $\mathrm{CO}_{2} \mathrm{R}$ Over Time By Age and Sex}

Based on the ROC curve analysis, a cut-point value of $2.7 \%$ was determined to be the threshold $\mathrm{CO}_{2} \mathrm{R}$ value that was most predictive of poor outcome across all ages. Thus, a $\mathrm{CO}_{2} \mathrm{R}$ value $<2.7 \%$ was considered to be abnormal, and this is consistent with the values used in previous studies. ${ }^{21,22}$ In the entire cohort, the majority of patients (53\%)

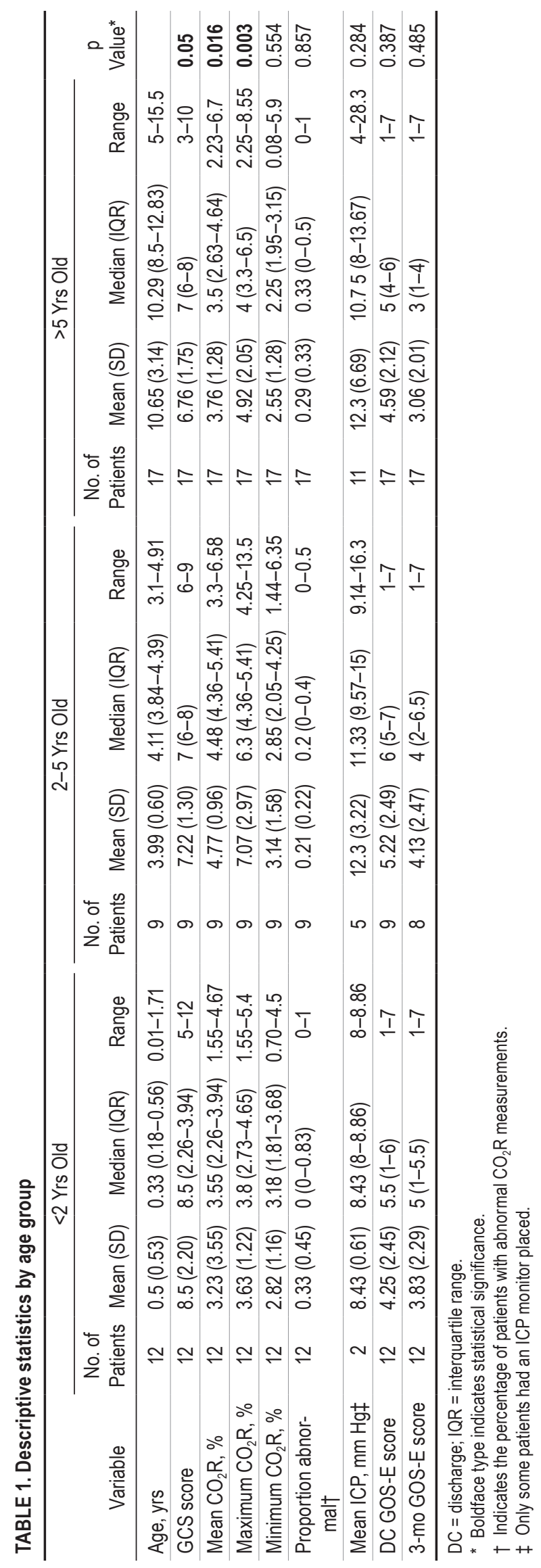

J Neurosurg Pediatr Volume 18 • July 2016 
had an abnormal mean $\mathrm{CO}_{2} \mathrm{R}$ for greater than $20 \%$ of their measurements. Those with severe TBI had impaired $\mathrm{CO}_{2} \mathrm{R}$ for $35 \%$ of the time compared with $10 \%$ for those with moderate TBI (22 severe and 9 moderate TBI patients) ( $\mathrm{p}$ $=0.029)$. Thirty-one patients $(22$ severe and 9 moderate TBI patients) were able to complete $\mathrm{CO}_{2} \mathrm{R}$ testing during the first 48 hours of admission, and, of these, $68 \%$ had impaired $\mathrm{CO}_{2} \mathrm{R}$ in at least 1 hemisphere during this time.

In the entire cohort, $\mathrm{CO}_{2} \mathrm{R}$ tended to improve over time. By Postinjury Day (PID) 3 to 4, nearly all patients had normalized their $\mathrm{CO}_{2} \mathrm{R}$. Of the 16 patients intubated longer than 4 days, 4 patients had impaired global $\mathrm{CO}_{2} \mathrm{R}$ values after this time point (Fig. 1). These patients who had abnormal $\mathrm{CO}_{2} \mathrm{R}$ later in their hospital course were intubated for longer $(p=0.016)$, had lower minimum $\mathrm{CO}_{2} \mathrm{R}$ values $(\mathrm{p}=0.047)$, and a greater proportion of impaired $\mathrm{CO}_{2} \mathrm{R}$ measurements than those whose $\mathrm{CO}_{2} \mathrm{R}$ remained steady or increased.

Children in the youngest age category $(<2$ years) had a lower mean $\mathrm{CO}_{2} \mathrm{R}$ over time (Fig. 2). The $2-5$-year-old age group had both significantly higher mean $\mathrm{CO}_{2} \mathrm{R}$ than the younger patients $(\mathrm{p}=0.016)$ and greater maximum $\mathrm{CO}_{2} \mathrm{R}$ than either of the other age groups $(p=0.003)($ Table 1$)$. Male patients initially had lower mean $\mathrm{CO}_{2} \mathrm{R}$ than female patients (Fig. 3). By PID 6, this relationship reverses. In those children with severe TBI, the effect of sex on $\mathrm{CO}_{2} \mathrm{R}$ over time is significant $(\mathrm{p}=0.019)$ and trends toward significance in those children with moderate TBI $(\mathrm{p}=0.067)$.

\section{Predictors of Abnormal $\mathrm{CO}_{2} \mathrm{R}$}

No variables that we evaluated (age, GCS score, ICP, Injury Severity Score, sex, MOI) were associated with an abnormal $\mathrm{CO}_{2} \mathrm{R}$.

\section{Outcome Correlation}

We found a statistically significant effect of the minimum recorded $\mathrm{CO}_{2} \mathrm{R}$ on the GOS-E Peds score at hospital discharge. On average, a 1-percentile increase in minimum $\mathrm{CO}_{2} \mathrm{R}$ decreases GOS-E Peds at discharge by 0.58 points $(\mathrm{p}=0.041)$. The proportion of abnormal mean $\mathrm{CO}_{2} \mathrm{R}$ values trends toward having a significant effect on the outcome score at discharge $(\mathrm{p}=0.104)$. Of the 12 patients who had an abnormal $\mathrm{CO}_{2} \mathrm{R}$ value in either hemisphere after 48 hours postinjury, all but 1 patient had poor neurological outcomes at discharge. Impaired $\mathrm{CO}_{2} \mathrm{R}$ beyond PID 4 showed a near-significant association with outcome at discharge $(\mathrm{p}=0.086)$.

\section{Discussion}

This is one of the few studies to describe $\mathrm{CO}_{2} \mathrm{R}$ in pe-

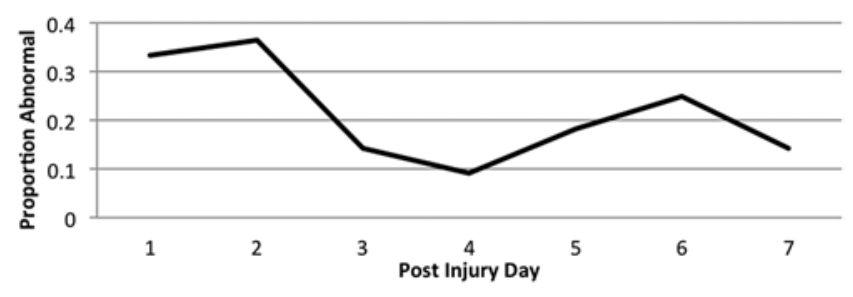

FIG. 1. Proportion of patients with abnormal $\mathrm{CO}_{2} \mathrm{R}$ over time.

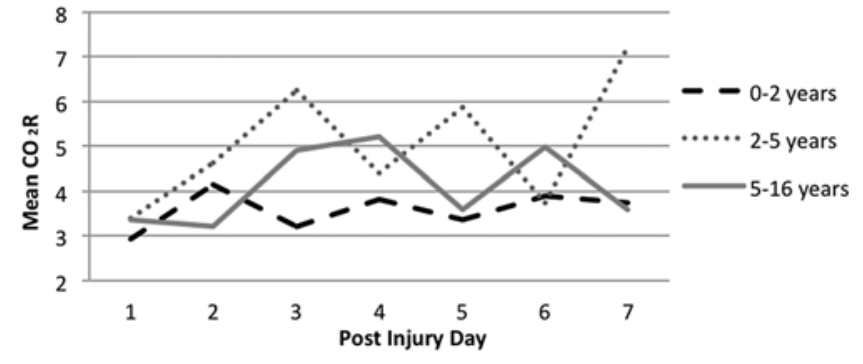

FIG. 2. $\mathrm{CO}_{2} \mathrm{R}$ over time by age group.

diatric age groups after the first 48 hours following TBI. Similar to other adult and pediatric studies, we found that it is common to have impaired $\mathrm{CO}_{2} \mathrm{R}$ within the first 48 hours after injury, $2,13,18$ and there were wide variations in timing, location, and duration of this impairment. ${ }^{1}$ Additionally, almost half of the patients who were still intubated after 48 hours had some impairment in either 1 or both hemispheres. There is a trend toward male patients initially having lower mean $\mathrm{CO}_{2} \mathrm{R}$ than female patients, but this relationship switches after PID 6 (Fig. 3). Baseline differences exist in $\mathrm{CO}_{2} \mathrm{R}$ and $\mathrm{CBF}$ between the sexes in healthy individuals, ${ }^{30}$ and so the sex differences in $\mathrm{CO}_{2} \mathrm{R}$ that we found in our cohort are not necessarily surprising. Similar to other studies, almost all our patients had normalized $\mathrm{CO}_{2} \mathrm{R}$ by PID 3 to $4 .{ }^{8,13,18}$ However, there were some individuals who had a late-onset or the recurrence of impaired $\mathrm{CO}_{2} \mathrm{R}$ after PID 4, which interestingly coincided with changes in clinical management (e.g., weaning of paralysis, sedation, and hyperosmolar therapy) or new imaging findings (e.g., carotid artery dissection and intracranial bleeding). All of these patients had poor GOS-E Peds scores at discharge. This suggests that the trend in $\mathrm{CO}_{2} \mathrm{R}$ after 48 hours postinjury and/or while weaning off ICP-controlling therapies may provide valuable data. Because this is a pilot study, future larger investigations could examine if impaired $\mathrm{CO}_{2} \mathrm{R}$ after 48 hours correlates with changes in management, new evolving injuries, and outcome.

Another aim of this study was to describe the patterns of impaired $\mathrm{CO}_{2} \mathrm{R}$ over time in different pediatric age groups after TBI. In our study, we found that the $2-5$-yearold age group had better preservation of $\mathrm{CO}_{2} \mathrm{R}$ compared with either of the other age groups. Children in the youngest age category $\left(<2\right.$ years old) had lower mean $\mathrm{CO}_{2} \mathrm{R}$ over time compared with the other age groups (Fig. 2). Adelson et al. conducted a retrospective chart review study in which 27 pediatric patients had $\mathrm{CO}_{2}$ vasoreactivity evaluated using $\mathrm{Xe} \mathrm{CT}$ in order to measure $\mathrm{CBF}$ measurements in response to $\mathrm{PaCO}_{2}$ changes. ${ }^{2}$ They found no correlation between age and impaired $\mathrm{CO}_{2} \mathrm{R}$; however, this patient population was divided into age groups that are different from the age groups used in our study (those younger than or older than 5 years), and $\mathrm{CO}_{2} \mathrm{R}$ was typically assessed once within the first 48 hours after injury rather than daily.

The age-based variations in $\mathrm{CO}_{2} \mathrm{R}$ over time that are evident in our patient population may be partly due to the diverse primary MOIs that result in the heterogeneity of brain damage. Some of our patients suffered abusive head trauma (AHT), and we had more of this MOI in 


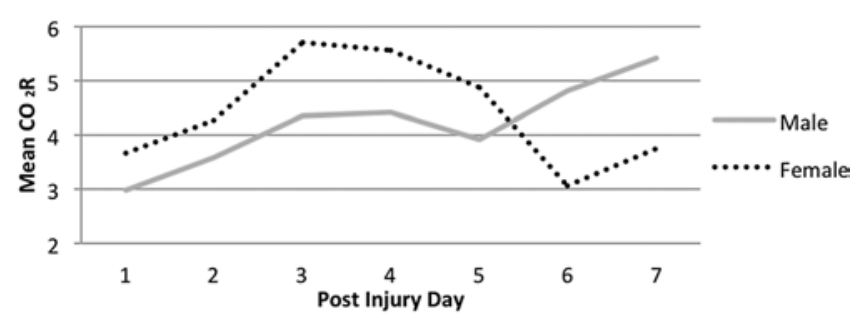

FIG. 3. $\mathrm{CO}_{2} \mathrm{R}$ over time by sex.

our younger-than-2-year-old age group compared with the other groups. Infants with AHT can present with apnea, and $\mathrm{CO}_{2} \mathrm{R}$ has been shown to be decreased and remain impaired after severe hypoxia. ${ }^{13,17,23}$ These abused patients may have also sustained repeated head trauma. However, we did not find a significant association between MOI and global mean $\mathrm{CO}_{2} \mathrm{R}$, which may be due to our small sample size. There were also no significant differences in global $\mathrm{CO}_{2} \mathrm{R}$ over time between those patients who suffered AHT versus any other MOI $(p=0.24)$. Table 2 shows the mean $\mathrm{CO}_{2} \mathrm{R}$ values by age group for each MOI. Additional studies with larger numbers of patients that are designed to evaluate the impact of $\mathrm{MOI}$ on $\mathrm{CO}_{2} \mathrm{R}$ and outcome are needed. Multiple studies involving adult patients have shown a link between poor neurological outcomes and impaired $\mathrm{CO}_{2} \mathrm{R}^{8,13,19-21,28}$ One pediatric study found patients with higher mean $\mathrm{CO}_{2} \mathrm{R}$ trended toward a more favorable outcome, and $\mathrm{CO}_{2} \mathrm{R}<2 \%$ torr $\mathrm{PaCO}_{2}$ in the first 48 hours after injury was correlated with poor neurological outcome at 6 months after injury. ${ }^{2}$ Similar to that study, our patients trended toward having an association between impaired $\mathrm{CO}_{2} \mathrm{R}$ in the first 48 hours after injury and poor neurological outcome at discharge. In our cohort, there was a significant relationship between the minimum recorded $\mathrm{CO}_{2} \mathrm{R}$ values over time and poor outcome scores at hospital discharge.

\section{Limitations}

TCD is a noninvasive, portable procedure that can be performed at bedside, making it a useful tool for repeated measurements and following changes in cerebral circulation after head injury. TCD can provide accurate, reproducible measurements of $\mathrm{CO}_{2} \mathrm{R}$ after TBI. ${ }^{11}$ It allows for assessment of mean blood flow velocity in the major cerebral arteries, but this value is not interchangeable with $\mathrm{CBF}^{24}$ We observed impaired $\mathrm{CO}_{2} \mathrm{R}$ in children after TBI, but it is unknown how this affected CBF in these patients.

There were several limitations to our study. This was a single-institution study with a relatively small sample size, and thus the results may not be generalizable. However, our sample size is similar to slightly larger than most other previously published $\mathrm{CO}_{2} \mathrm{R}$ studies on pediatric TBI. Future studies should examine similar aims in larger cohorts of patients. Another limitation is that some of our sickest patients had missing data in the first 48 hours after injury due to tight $\mathrm{PaCO}_{2}$ regulation by the clinical team, resulting in $\mathrm{ETCO}_{2}<35 \mathrm{~mm} \mathrm{Hg}$. We did not further hyperventilate these patients to prevent additional ischemia and brain injury. In other patients, we were unable to lower $\mathrm{ETCO}_{2}$ with ventilator adjustments due to either concurrent lung injury or abnormal respiratory patterns, leading to ven-
TABLE 2. Mean global $\mathrm{CO}_{2} \mathrm{R}$ values by age group and MOI

\begin{tabular}{lccc}
\hline \multirow{2}{*}{ MOI } & \multicolumn{3}{c}{ Mean (no. of patients) } \\
\cline { 2 - 4 } & $<2$ Yrs & $2-5$ Yrs & $>5$ Yrs \\
\hline Fall & $3.35(3)$ & & $2.47(1)$ \\
\hline Motor vehicle accident & & $4.96(6)$ & $4.02(5)$ \\
\hline Pedestrian vs auto & $3.91(2)$ & $4.25(1)$ & $3.51(5)$ \\
\hline AHT & $2.97(7)$ & $4.78(1)$ & $3.38(2)$ \\
\hline Other $^{*}$ & & $4.45(1)$ & $4.06(4)$ \\
\hline
\end{tabular}

* Other includes gunshot to head, all-terrain vehicle accident, and unknown.

tilator dyssynchrony. Statistical analyses were adjusted appropriately to account for missing data, but our results may still have underestimated the prevalence and association of impaired $\mathrm{CO}_{2} \mathrm{R}$ on outcome.

Lastly, limited normative data for $\mathrm{CO}_{2} \mathrm{R}$ in children exist. Karsli et al. evaluated healthy children who were anesthetized with propofol and found that $\mathrm{CO}_{2} \mathrm{R}$ ranged from $10.3 \%$ to $13.8 \%$ over a wide range of $\mathrm{ETCO}_{2}$ values (range $25-55 \mathrm{~mm} \mathrm{Hg}) \cdot{ }^{10}$ Other pediatric studies have found a value of $<2 \%$ in the first 48 hours after injury to be associated with poor neurological outcome. ${ }^{2,5}$ Based on the limited available data and ROC curve analysis of our data, we considered a threshold of $<2.7 \%$ as abnormal. Due to small patient numbers affecting the validity of results, we could not use regression models to generate age-specific thresholds.

\section{Conclusions}

Abnormal $\mathrm{CO}_{2} \mathrm{R}$ is prevalent in children following TBI and can occur after the initial 48 hours postinjury. There are no obvious predictors that identify those who will have abnormal vasoreactivity. Lower minimum $\mathrm{CO}_{2} \mathrm{R}$ values over time are associated with worse GOS-E Peds scores at hospital discharge.

\section{Acknowledgments}

This work was supported by an intramural funding grant from the Research Institute at Nationwide Children's Hospital, Columbus, Ohio. The project described was supported by a grant (no. UL1TR001070) from the National Center for Advancing Translational Sciences. The content is solely the responsibility of the authors and does not necessarily represent the official views of the National Center for Advancing Translational Sciences or the National Institutes of Health.

\section{References}

1. Adelson PD, Clyde B, Kochanek PM, Wisniewski SR, Marion DW, Yonas H: Cerebrovascular response in infants and young children following severe traumatic brain injury: a preliminary report. Pediatr Neurosurg 26:200-207, 1997

2. Adelson PD, Srinivas R, Chang Y, Bell M, Kochanek PM: Cerebrovascular response in children following severe traumatic brain injury. Childs Nerv Syst 27:1465-1476, 2011

3. Aldrich EF, Eisenberg HM, Saydjari C, Luerssen TG, Foulkes MA, Jane JA, et al: Diffuse brain swelling in severely head-injured children. A report from the NIH Traumatic Coma Data Bank. J Neurosurg 76:450-454, 1992

4. Beers SR, Wisniewski SR, Garcia-Filion P, Tian Y, Hahner $\mathrm{T}$, Berger RP, et al: Validity of a pediatric version of the 
Glasgow Outcome Scale-Extended. J Neurotrauma 29:1126-1139, 2012

5. Cold GE, Jensen FT, Malmros R: The cerebrovascular $\mathrm{CO}_{2}$ reactivity during the acute phase of brain injury. Acta Anaesthesiol Scand 21:222-231, 1977

6. Faul M, Xu L, Wald MM, Coronado VG: Traumatic Brain Injury in the United States: Emergency Department Visits, Hospitalizations, and Deaths 2002-2006. Atlanta: Centers for Disease Control and Prevention, National Center for Injury Prevention and Control, 2010

7. Freeman SS, Udomphorn Y, Armstead WM, Fisk DM, Vavilala MS: Young age as a risk factor for impaired cerebral autoregulation after moderate to severe pediatric traumatic brain injury. Anesthesiology 108:588-595, 2008

8. Haenggi M, Andermatt A, Anthamatten C, Galimanis A, Mono ML, Alfieri A, et al: $\mathrm{CO}_{2}$ )-Dependent vasomotor reactivity of cerebral arteries in patients with severe traumatic brain injury: time course and effect of augmentation of cardiac output with dobutamine. J Neurotrauma 29:1779-1784, 2012

9. Ide K, Eliasziw M, Poulin MJ: Relationship between middle cerebral artery blood velocity and end-tidal $\mathrm{PCO}_{2}$ in the hypocapnic-hypercapnic range in humans. J Appl Physiol (1985) 95:129-137, 2003

10. Karsli C, Luginbuehl I, Farrar M, Bissonnette B: Cerebrovascular carbon dioxide reactivity in children anaesthetized with propofol. Paediatr Anaesth 13:26-31, 2003

11. Klingelhöfer J, Sander D: Doppler $\mathrm{CO}_{2}$ test as an indicator of cerebral vasoreactivity and prognosis in severe intracranial hemorrhages. Stroke 23:962-966, 1992

12. Kochanek PM, Carney N, Adelson PD, Ashwal S, Bell MJ, Bratton S, et al: Guidelines for the acute medical management of severe traumatic brain injury in infants, children, and adolescents-second edition. Pediatr Crit Care Med 13 Suppl:S1-S82, 2012

13. Lee JH, Kelly DF, Oertel M, McArthur DL, Glenn TC, Vespa $\mathrm{P}$, et al: Carbon dioxide reactivity, pressure autoregulation, and metabolic suppression reactivity after head injury: a transcranial Doppler study. J Neurosurg 95:222-232, 2001

14. Leon JE, Bissonnette B: Cerebrovascular responses to carbon dioxide in children anaesthetized with halothane and isoflurane. Can J Anaesth 38:817-825, 1991

15. Levin HS, Eisenberg HM, Wigg NR, Kobayashi K: Memory and intellectual ability after head injury in children and adolescents. Neurosurgery 11:668-673, 1982

16. Luerssen TG, Klauber MR, Marshall LF: Outcome from head injury related to patient's age. A longitudinal prospective study of adult and pediatric head injury. J Neurosurg 68:409-416, 1988

17. Maguire S, Pickerd N, Farewell D, Mann M, Tempest V, Kemp AM: Which clinical features distinguish inflicted from non-inflicted brain injury? A systematic review. Arch Dis Child 94:860-867, 2009

18. Martin NA, Patwardhan RV, Alexander MJ, Africk CZ, Lee $\mathrm{JH}$, Shalmon E, et al: Characterization of cerebral hemodynamic phases following severe head trauma: hypoperfusion, hyperemia, and vasospasm. J Neurosurg 87:9-19, 1997

19. Messeter K, Nordström CH, Sundbärg G, Algotsson L, Ryding E: Cerebral hemodynamics in patients with acute severe head trauma. J Neurosurg 64:231-237, 1986

20. Nordström CH, Messeter K, Sundbärg G, Schalén W, Werner M, Ryding E: Cerebral blood flow, vasoreactivity, and oxygen consumption during barbiturate therapy in severe traumatic brain lesions. J Neurosurg 68:424-431, 1988

21. Poon WS, Zhu XL, Ng SC, Wong GK: Predicting one year clinical outcome in traumatic brain injury (TBI) at the begin- ning of rehabilitation. Acta Neurochir Suppl 93:207-208, 2005

22. Puppo C, Fariña G, López FL, Caragna E, Biestro A: Cerebral $\mathrm{CO}_{2}$ reactivity in severe head injury. A transcranial Doppler study. Acta Neurochir Suppl 102:171-175, 2008

23. Quint SR, Scremin OU, Sonnenschein RR, Rubinstein EH: Enhancement of cerebrovascular effect of $\mathrm{CO} 2$ by hypoxia. Stroke 11:286-289, 1980

24. Reinstrup P, Ryding E, Asgeirsson B, Hesselgard K, Unden J, Romner B: Cerebral blood flow and transcranial Doppler sonography measurements of $\mathrm{CO}_{2}$-reactivity in acute traumatic brain injured patients. Neurocrit Care 20:54-59, 2014

25. Roozenbeek B, Maas AI, Menon DK: Changing patterns in the epidemiology of traumatic brain injury. Nat Rev Neurol 9:231-236, 2013

26. Rowney DA, Fairgrieve R, Bissonnette B: Cerebrovascular carbon dioxide reactivity in children anaesthetized with sevoflurane. Br J Anaesth 88:357-361, 2002

27. Scaife ER, Statler KD: Traumatic brain injury: preferred methods and targets for resuscitation. Curr Opin Pediatr 22:339-345, 2010

28. Schalén W, Messeter K, Nordström CH: Cerebral vasoreactivity and the prediction of outcome in severe traumatic brain lesions. Acta Anaesthesiol Scand 35:113-122, 1991

29. Settergren G, Lindblad BS, Persson B: Cerebral blood flow and exchange of oxygen, glucose ketone bodies, lactate, pyruvate and amino acids in anesthetized children. Acta Paediatr Scand 69:457-465, 1980

30. Tontisirin N, Muangman SL, Suz P, Pihoker C, Fisk D, Moore A, et al: Early childhood gender differences in anterior and posterior cerebral blood flow velocity and autoregulation. Pediatrics 119:e610-e615, 2007

31. Udomphorn Y, Armstead WM, Vavilala MS: Cerebral blood flow and autoregulation after pediatric traumatic brain injury. Pediatr Neurol 38:225-234, 2008

32. Wasserman AJ, Patterson JL Jr: The cerebral vascular response to reduction in arterial carbon dioxide tension. J Clin Invest 40:1297-1303, 1961

33. Zwienenberg M, Muizelaar JP: Severe pediatric head injury: the role of hyperemia revisited. J Neurotrauma 16:937-943, 1999

\section{Disclosures}

The authors report no conflict of interest concerning the materials or methods used in this study or the findings specified in this paper.

\section{Author Contributions}

Conception and design: Maa, Yeates, O'Brien. Acquisition of data: Maa, Yeates, O'Brien. Analysis and interpretation of data: all authors. Drafting the article: Maa, Moore-Clingenpeel, O'Brien. Critically revising the article: Maa, Moore-Clingenpeel, O'Brien. Reviewed submitted version of manuscript: Maa, Moore-Clingenpeel, O'Brien. Approved the final version of the manuscript on behalf of all authors: Maa. Statistical analysis: Moore-Clingenpeel, O'Brien. Administrative/technical/material support: O’Brien. Study supervision: Maa, Yeates, O’Brien.

\section{Correspondence}

Tensing Maa, Nationwide Children's Hospital, Division of Critical Care, 700 Children's Dr., ED 357, Columbus, OH 43205. email: tensing.maa@nationwidechildrens.org. 